\title{
Adsorption of ethanol onto phenol resin based adsorbents for developing next generation cooling systems
}

\author{
Ibrahim I. El-Sharkawy ${ }^{1,3,5}$, Kutub Uddin ${ }^{2,5}$, Takahiko Miyazaki ${ }^{1,5}$, Bidyut Baran Saha ${ }^{2,5, *}$, \\ Shigeru Koyama ${ }^{1,2,5}$, Hyun-Sig Kil ${ }^{2}$, Seong-Ho Yoon ${ }^{2,4}$, Jin Miyawaki ${ }^{2,4,6}$ \\ ${ }^{1}$ Faculty of Engineering Sciences, Kyushu University \\ Kasuga-koen 6-1, Kasuga-shi, Fukuoka 816-8580, Japan \\ ${ }^{2}$ Interdisciplinary Graduate School of Engineering Sciences, Kyushu University \\ Kasuga-koen 6-1, Kasuga-shi, Fukuoka 816-8580, Japan \\ ${ }^{3}$ Mechanical Power Engineering Department, Faculty of Engineering \\ Mansoura University, El-Mansoura 35516, Egypt \\ ${ }^{4}$ Institute for Materials Chemistry and Engineering, Kyushu University \\ Kasuga-koen 6-1, Kasuga-shi, Fukuoka 816-8580, Japan \\ ${ }^{5}$ International Institute for Carbon-Neutral Energy Research (WPI-I2CNER), Kyushu University \\ 744 Motooka, Nishi-ku, Fukuoka 819-0395, Japan \\ ${ }^{6}$ Research and Education Center for Advanced Energy Materials, Devices, and Systems \\ Kyushu University, Kasuga-koen 6-1, Kasuga-shi, Fukuoka 816-8580, Japan \\ *Author to whom correspondence should be addressed, E-mail: \\ saha.baran.bidyut.213@m.kyushu-u.ac.jp
}

\begin{abstract}
Adsorption characteristics of ethanol onto two promising adsorbents have been investigated for developing high performance adsorption chillers. These new adsorbents are based on spherical phenol resin treated with different mass ratios of $\mathrm{KOH}$ named as KOH4-PR and KOH6-PR. Experimental adsorption isotherm measurements show that the adsorption capacity of KOH4$\mathrm{PR} /$ ethanol is as high as $1.43 \mathrm{~kg} \mathrm{~kg}^{-1}$ whilst one $\mathrm{kg}$ of KOH6-PR able to adsorb nearly about $2 \mathrm{~kg}$ of ethanol. To the best of our knowledge, the studied adsorbents possess the highest ethanol uptake. Moreover, it is found that the KOH4-PR/ethanol pair has notably high adsorption
\end{abstract}


kinetics at the lower range of adsorption temperatures. Experimental measurements of adsorption uptake and adsorption uptake rate of the studied pairs have been analyzed and isosteric heats of adsorption have also been extracted.

Key words: adsorption cooling; adsorption isotherms; ethanol; kinetics, phenol resin

\section{Nomenclature}




$\mathrm{W}_{\mathrm{o}} \quad$ maximum adsorption capacity $\left(\mathrm{kg} \mathrm{kg}^{-1}\right)$

\section{Introduction}

According to International Institute of Refrigeration (IIR), approximately 15\% of electricity produced in the world has been utilized for refrigeration and air-conditioning applications [1, 2]. The intensive use of air conditioning during summer periods, especially in hot climate regions, increases the peak of electricity demand. Adsorption cooling systems could be an effective option in reducing the peak electrical demand as they can be driven by solar energy or low-grade waste heat typically below $100{ }^{\circ} \mathrm{C}$. Moreover, these systems are environmental friendly since they use natural refrigerants or alcohols such as water, ethanol and methanol. However, the main hindrance for spreading this technology is the poor system performance and bulkiness due to the limitation of sorption capacity of adsorbent material and the low heat transfer rate inside adsorber/desorber reactors. Therefore, characterization of innovative and promising pairs that possess high adsorption uptake and/or fast kinetics becomes a hot research topic for developing high performance adsorption cooling systems. The working pairs can be classified as pairs working at partial sub-atmospheric pressure which dominated mainly by silica gel/water, zeolite/water, activated carbon (AC)/methanol, activated carbon/ethanol and activated carbon fibers $(\mathrm{ACFs})+$ ethanol or methanol. Pairs working at pressurized conditions such as AC/ammonia, AC/butane, AC /R134a and others. Adsorption characteristics of water onto two types of silica gel namely A and RD have been experimentally investigated using volumetric method [3]. The measurements have been conducted within a temperature ranges from 298 to $338 \mathrm{~K}$ and pressure ranges from 500 to $700 \mathrm{~Pa}$. Adsorption isotherm data have been correlated 
using Tóth equation and isosteric heat of adsorption has been evaluated. Aristov et al. [4] measured the water sorption equilibrium and specific heat of water onto a family of composite materials called selective water sorbents. These materials consist of a porous host matrix with open pores and a hygroscopic substance impregnated into its pores. Authors reported that composites based on $\mathrm{CaCl}_{2}$ and $\mathrm{LiBr}$ as impregnated salts and different micro- and mesoporous silica gels as host matrices have adsorption capacity as high as $0.75 \mathrm{~kg} \mathrm{~kg}^{-1}$. Solmuş et al. [5] measured adsorption isotherms of natural zeolite/water pair for adsorption cooling applications. The Dubinin-Astakhov adsorption isotherm model has been used to fit the experimental data. They reported that the maximum adsorption capacity of natural zeolite is about $0.12 \mathrm{~kg} \mathrm{~kg}^{-1}$ for adsorption temperature ranges from 40 to $150{ }^{\circ} \mathrm{C}$ and evaporation pressure from 0.87 to 7.38 kPa. El-Sharkawy et al. [6] measured adsorption uptake of ethanol onto two types of activated carbon fibers namely $\mathrm{ACF}(\mathrm{A}-20)$ and $\mathrm{ACF}(\mathrm{A}-15)$. It is reported that one $\mathrm{kg}$ of $\mathrm{ACF}$ (A-20) has the ability to adsorb about $0.797 \mathrm{~kg}$ of ethanol whilst ACF (A-15) has adsorption capacity of about $0.57 \mathrm{~kg} \mathrm{~kg}^{-1}$. The study also addressed the effect of packing density of adsorbent on adsorption rate. El-Sharkawy et al. [7] studied the adsorption characteristics of ethanol onto parent and surface treated activated carbon powder. Adsorption isotherms and kinetics of ethanol onto three adsorbents namely, parent Maxsorb III, $\mathrm{KOH}-\mathrm{H}_{2}$ treated Maxsorb III, and $\mathrm{H}_{2}$ treated Maxsorb III have been measured gravimetrically. It is found that the maximum adsorption uptakes of ethanol onto $\mathrm{H}_{2}$ treated Maxsorb III, parent Maxsorb III and $\mathrm{KOH}-\mathrm{H}_{2}$ treated Maxsorb III are 1.23, 1.20 and $1.01 \mathrm{~kg} \mathrm{~kg}^{-1}$, respectively. However, adsorption kinetics of $\mathrm{KOH}-$ $\mathrm{H}_{2}$ treated Maxsorb III/ethanol pair is faster than other two studied pairs. Gordeeva and Aristov [8] presented the dynamic characteristics of methanol adsorption onto activated carbon ACM- 
35.4 for enhancing the specific cooling power of the adsorption chillers. The study addressed the effects of adsorbent grain size, bed thickness and adsorption/desorption temperatures under conditions close to real adsorption chiller operations. Tamainot-Telto et al. [9] studied the adsorption characteristics of ammonia onto 26 different activated carbons. They used a thermodynamic cycle model coupled with adsorption isotherm equations to select the optimum pair based on the cooling/heating production and/or coefficient of performance. Adsorption characteristics of other pairs could be found elsewhere [10-19].

This study presents an experimental investigation of ethanol adsorption onto two newly developed phenol resin based adsorbents namely KOH4-PR and KOH6-PR. Adsorption isotherms and kinetics of the studied pairs have been measured gravimetrically using magnetic suspension adsorption measurement unit. Experimental data have been analyzed and correlated with popular adsorption isotherm and kinetic models. Adsorption uptakes of ethanol onto the studied adsorbents are found to be very promising which may lead to the design and development of high performance adsorption chillers.

\section{Adsorbents}

Spherical phenol resin samples, as provided BEAPS ${ }^{\circledR}$ series (Asahi Organic Chemicals Industry Co., Ltd.), have been used as a raw material. The BEAPS ${ }^{\circledR}$ which is a registered trademark of Asahi Organic Chemicals Industry Co., Ltd. has been carbonized at $600{ }^{\circ} \mathrm{C}$ for an hour in a flow of $\mathrm{N}_{2}$ using a vertical electric furnace. For the preparation of activated carbons, potassium hydroxide (purity $>85.0 \%$, Wako Pure Chemical Industries, Ltd.) is used as an activating agent. Weight ratio of $\mathrm{KOH} / \mathrm{carbonized}$ BEAPS has set to 4 or 6 . The mixture of $\mathrm{KOH}$ and the 
carbonized BEAPS ${ }^{\circledR}$ has been put in a nickel container, and then the nickel container is located in a stainless steel container. After that, the stainless steel container is placed in an electric furnace vertically. The mixture is heat-treated up to $900{ }^{\circ} \mathrm{C}$ at a heating rate of $5{ }^{\circ} \mathrm{C} / \mathrm{min}$ and maintained at $900{ }^{\circ} \mathrm{C}$ for one hour under $\mathrm{N}_{2}$ flow. After the activation, the remaining $\mathrm{KOH}$ and salts formed during the heat treatment are removed by the washing with $\mathrm{HCl}$ solution for three times and deionized water once to adjust $\mathrm{pH}$ to be about 7. After washing, the collected samples are dried at $100{ }^{\circ} \mathrm{C}$ for 3 hours in an air oven and dried again at $150{ }^{\circ} \mathrm{C}$ for 12 hours in a vacuum oven. Figure 1 shows the SEM pictures of both KOH4-PR and KOH6-PR samples whilst their porosity and elemental composition are furnished in Table 1.

Laser Diffraction Particle Size Analyzer, SALD-2300, supplied by Shimadzu Corporation, Japan is used to measure the particle size distribution of adsorbent. Figures 2(a) and 2(b) show the particle size distributions for KOH4-PR and KOH6-PR samples. It can be seen from Figures 2(a) and 2(b) that both adsorbent samples have narrow particle size distributions and the normalized particle amount reaches $50 \%$ at particle diameters of 26 and $23 \mu \mathrm{m}$ for KOH4-PR and KOH6-PR, respectively.

\section{Experiments}

Magnetic suspension adsorption measurement unit of type (MSB-VG-S2) supplied by BEL Japan, Inc. is used to measure adsorption isotherms and kinetics of the studied pairs. For each adsorption isotherm, the sample temperature is kept constant whilst evaporator temperature increases stepwise until reaches a relative pressure of about 0.9 or above. Experiments have been conducted at adsorption temperatures of 30, 40, 50, 60 and $70{ }^{\circ} \mathrm{C}$. For the experimental 
isotherm and kinetics measurement of both studied samples, a $47 \mathrm{mg}$ of dry sample has been used. Ethanol of $99.5 \%$ purity supplied by Osaka Kishida Chemical Co., Ltd., Japan is used as adsorbate. Experimental procedure has been described in detail by El-Sharkawy et al. [7].

\section{Results and discussion}

\subsection{Adsorption isotherms}

Figures 3(a) and 3(b) show adsorption isotherms of KOH4-PR/ethanol and KOH6-PR/ethanol pairs. It can be seen that one $\mathrm{kg}$ of KOH4-PR type adsorbent can adsorb $1.43 \mathrm{~kg}$ of ethanol whilst KOH6-PR has an adsorption capacity as high as about $2 \mathrm{~kg} \mathrm{~kg}^{-1}$. Repeatability of the experimental adsorption isotherm data is also confirmed. To the best of our knowledge, adsorption uptakes of ethanol onto the two studied spherical phenol resin based adsorbents are significantly higher than adsorption capacity of ethanol onto any other adsorbent. It is worthy to mention that, adsorption capacity of KOH6-PR/ethanol pair is about $40 \%$ higher than that of KOH4-PR/ethanol pair. This is might be due to the difference between the micropore volumes of both adsorbents since KOH6-PR possesses micropore volume of $2.37 \mathrm{~cm}^{3} \mathrm{~g}^{-1}$ whilst $\mathrm{KOH} 4-$ PR has $1.85 \mathrm{~cm}^{3} \mathrm{~g}^{-1}$.

The Dubinin-Raduskevich (D-R) equation (Eq. 1) is used to fit the adsorption isotherms of KOH4-PR/ethanol pair whilst the Dubinin-Astakhov (D-A) equation (Eq. 2) is found to be more suitable for KOH6-PR/ethanol pair. Numerical values of adsorption isotherm parameters are furnished in Table 2. 


$$
\begin{aligned}
& W=W_{0} \exp \left[-\left(\frac{R_{g} T}{E} \ln \left(\frac{P_{s}}{P}\right)\right)^{2}\right] \\
& W=W_{0} \exp \left[-\left(\frac{R_{g} T}{E} \ln \left(\frac{P_{s}}{P}\right)\right)^{n}\right]
\end{aligned}
$$

Figures 4(a) and (b) show the adsorption/desorption isotherms for KOH4-PR/ethanol pair at adsorption temperatures of 30 and $70^{\circ} \mathrm{C}$, respectively. Similar plots for KOH6-PR/ethanol pair are shown in Figures 4(c) and 4(d). It is visible that, there is no hysterics for the studied pairs.

\subsection{Adsorption kinetics}

Figures 5(a) and 5(b) show the plots of adsorption uptake and pressure versus time at adsorption temperature of $30{ }^{\circ} \mathrm{C}$ for both $\mathrm{KOH} 4-\mathrm{PR} /$ ethanol and $\mathrm{KOH} 6-\mathrm{PR} / \mathrm{ethanol}$ pairs. As can be seen from Figure 5(a), adsorption uptake of ethanol onto KOH4-PR increases significantly at low relative pressure however, it increases marginally at relatively higher relative pressures. On the other hand, the increase in adsorption uptake of KOH6-PR/ethanol pair is almost constant within the whole experimental relative pressure span (see Fig. 5(b)). This is proven by the trend of adsorption isotherms of the studied pairs as can be seen from Figs. 3(a) and 3(b).

The diffusion time constant is evaluated using the Fickian diffusion model [20] for both pairs. As the studied adsorbents have spherical shapes (see Fig. 1), the fractional uptake can be calculated using Eq. 3 below [21],

$$
F=\frac{w-w_{i n}}{W-w_{i n}}=1-\frac{6}{\pi^{2}} \sum_{n=1}^{\infty} \frac{1}{n^{2}} \exp \left(-\frac{n^{2} \pi^{2} D t}{R_{p}^{2}}\right)
$$


Equation (3) can be simplified to Eq. (4) at longer adsorption time [22],

$$
F=1-\frac{6}{\pi^{2}} \exp \left(-\pi^{2} \frac{D t}{R_{p}^{2}}\right)
$$

The diffusion time constant $\left(\mathrm{D} / \mathrm{R}_{\mathrm{p}}{ }^{2}\right)$ can be estimated by the linear plots of $\ln (1-\mathrm{F})$ versus time, $\mathrm{t}$ [22-24]. Figures 6(a) and 6(b) show the plot of $\ln (1-\mathrm{F})$ versus time at adsorption temperature of $30{ }^{\circ} \mathrm{C}$ and certain equilibrium pressures for KOR4-PR/ethanol and KOH6-PR/ethanol pairs. The diffusion time constant is evaluated at each adsorption step and the average values are evaluated at conditions suitable for adsorption chiller operation. Arrhenius equation (Eq. 5) is used to investigate the effect of temperature on the diffusion time constant. Arrhenius plots of the studied pairs are presented in Figure 7.

$$
D=D_{s o} \exp \left(\frac{-E_{a}}{R_{g} T}\right)
$$

Therefore,

$$
\ln \left(\frac{D}{R_{p}^{2}}\right)=-\ln \left(\frac{D_{s o}}{R_{p}^{2}}\right)-\left(\frac{E_{a}}{R_{g}}\right)\left(\frac{1}{T}\right)
$$

As can be seen from Fig. 7, the diffusion time constant of the KOH4-PR/ethanol pair is significantly higher than that of the KOH6-PR/ethanol pair at low adsorption temperature. Numerical values of $\left(D_{\mathrm{so}} / \mathrm{R}_{\mathrm{p}}{ }^{2}\right)$ and activation energy of the studied pairs are furnished in Table 3 . The diffusion time constants as a function of temperature for both KOH4-PR/ethanol and KOH6PR/ethanol pairs are given by Eq. (7) and Eq. (8), respectively. 


$$
\ln \left(\frac{D}{R_{p}^{2}}\right)=-4.987-\frac{898.16}{T}
$$

$$
\ln \left(\frac{D}{R_{p}^{2}}\right)=-1.349-\frac{2133.3}{T}
$$

As can be noticed from Eqs. (7) and (8), the diffusion time constant for KOH6-PR/ethanol pair strongly depends on the adsorption temperature.

\subsection{Isosteric heat of adsorption}

Isosteric heat of adsorption at constant adsorption uptake is commonly estimated using the Clausius-Clapeyron equation as given by Eq. (9) below;

$\left.q_{s t}\right|_{C C}=-R_{g} \frac{\partial \ln P}{\partial(1 / T)}$

It is proven that the isosteric heat of adsorption depends on adsorption uptake and temperature. Here, the isosteric heats of adsorption of the studied pairs are estimated using Eq. (10) which was proposed by the same authors [25].

$q_{s t}=-\left(R_{g} T^{2} \frac{\partial}{\partial T} \ln \left(P_{s}\right)+E\left\{-\ln \left(\frac{W}{W_{0}}\right)\right\}^{1 / n}\right)$

Figures 8(a) and 8(b) show the plots of $\mathrm{q}_{\mathrm{st}}$ versus adsorption uptake for KOH4-PR/ethanol and KOH6-PR/ethanol pairs at adsorption temperatures of 30,50 and $70{ }^{\circ} \mathrm{C}$. It is evident that the 
isosteric heats of adsorption of the studied pairs decrease with the increase of adsorption uptake and $\mathrm{q}_{\mathrm{st}}$ of KOH6-PR/ethanol pair is slightly lower than that of KOH4-PR/ethanol pair.

\section{Conclusions}

Adsorption equilibrium and kinetics of ethanol onto two spherical phenol resin based adsorbents treated with different mass ratios of $\mathrm{KOH}$ have been measured gravimetrically. Adsorption uptake of ethanol onto the studied adsorbents named KOH4-PR and KOH6-PR are as high as $1.43 \mathrm{~kg} \mathrm{~kg}^{-1}$ and $2 \mathrm{~kg} \mathrm{~kg}^{-1}$, respectively. Results obtained from the present study show that adsorption capacity of $\mathrm{KOH} 4-\mathrm{PR} /$ ethanol and $\mathrm{KOH} 6-\mathrm{PR} /$ ethanol are higher than adsorption uptake of ethanol onto any other adsorbents available in the open literatures. Results of the adsorption kinetics show that KOH4-PR/ethanol pair has a higher kinetics compared to that of the KOH6-PR/ethanol pair at low adsorption temperatures. Isosteric heats of adsorption for both pairs have also been estimated using adsorption isotherm data. Results extracted from this study show that the newly developed adsorbents have promising adsorption characteristics with ethanol that may lead to the development of next generation of adsorption chillers.

\section{Acknowledgements}

This work was financially supported by Japan Science and Technology Agency (JST), Core

Research for Evolutional Science and Technology (CREST). Authors also thank to Asahi Organic Chemicals Industry Co., Ltd., Japan for providing BEAPS ${ }^{\circledR}$ samples. 


\section{References}

[1] I.I. El-Sharkawy, H. AbdelMeguid, B.B. Saha, Potential application of solar powered adsorption cooling systems in the Middle East, Applied Energy, 126 (2014) 235-245.

[2] B. Choudhury, P.K. Chatterjee, J.P. Sarkar, Review paper on solar-powered air-conditioning through adsorption route, Renewable and Sustainable Energy Reviews, 14(8) (2010) 2189-2195.

[3] H.T. Chua, K.C. Ng, A. Chakraborty, N.M. Oo, M.A. Othman, Adsorption characteristics of silica gel + water systems, Journal of Chemical and Engineering Data, 47(5) (2002) 1177-1181.

[4] Y.I. Aristov, G. Restuccia, G. Cacciola, V.N. Parmon, A family of new working materials for solid sorption air conditioning systems, Applied Thermal Engineering, 22(2) (2002) 191-204.

[5] İ. Solmuş, C. Yamalı, B. Kaftanoğlu, D. Baker, A. Çağlar, Adsorption properties of a natural zeolite-water pair for use in adsorption cooling cycles, Applied Energy, 87(6) (2010) 2062-2067.

[6] I.I. El-Sharkawy, K. Kuwahara, B.B. Saha, S. Koyama, K.C. Ng, Experimental investigation of activated carbon fibers/ethanol pairs for adsorption cooling system application, Applied Thermal Engineering, 26(8-9) (2006) 859-865.

[7] I.I. El-Sharkawy, K. Uddin, T. Miyazaki, B.B. Saha, S. Koyama, J. Miyawaki, S.-H. Yoon, Adsorption of ethanol onto parent and surface treated activated carbon powders, International Journal of Heat and Mass Transfer, 73 (2014) 445-455.

[8] L. Gordeeva, Y. Aristov, Dynamic study of methanol adsorption on activated carbon ACM35.4 for enhancing the specific cooling power of adsorptive chillers, Applied Energy, 117 (2014) $127-133$.

[9] Z. Tamainot-Telto, S.J. Metcalf, R.E. Critoph, Y. Zhong, R. Thorpe, Carbon-ammonia pairs for adsorption refrigeration applications: ice making, air conditioning and heat pumping, International Journal of Refrigeration, 32(6) (2009) 1212-1229. 
[10] S.K. Henninger, M. Schicktanz, P.P.C. Hügenell, H. Sievers, H.M. Henning, Evaluation of methanol adsorption on activated carbons for thermally driven chillers part I: Thermophysical characterisation, International Journal of Refrigeration, 35(3) (2012) 543-553.

[11] E. Passos, F. Meunier, J.C. Gianola, Thermodynamic performance improvement of an intermittent solar-powered refrigeration cycle using adsorption of methanol on activated carbon, Journal of Heat Recovery Systems, 6(3) (1986) 259-264.

[12] B.B. Saha, I.I. El-Sharkawy, R. Thorpe, R.E. Critoph, Accurate adsorption isotherms of R134a onto activated carbons for cooling and freezing applications, International Journal of Refrigeration, 35(3) (2012) 499-505.

[13] B.B. Saha, K. Habib, I.I. El-Sharkawy, S. Koyama, Adsorption characteristics and heat of adsorption measurements of R-134a on activated carbon, International Journal of Refrigeration, 32(7) (2009) 1563-1569.

[14] I.I. El-Sharkawy, M. Hassan, B.B. Saha, S. Koyama, M.M. Nasr, Study on adsorption of methanol onto carbon based adsorbents, International Journal of Refrigeration, 32(7) (2009) 1579-1586.

[15] S.K. Henninger, F.P. Schmidt, H.M. Henning, Water adsorption characteristics of novel materials for heat transformation applications, Applied Thermal Engineering, 30(13) (2010) 1692-1702.

[16] Y.I. Aristov, Adsorptive transformation of heat: Principles of construction of adsorbents database, Applied Thermal Engineering, 42 (2012) 18-24.

[17] B.B. Saha, S. Jribi, S. Koyama, I.I. El-Sharkawy, Carbon dioxide adsorption isotherms on activated carbons, Journal of Chemical \& Engineering Data, 56(5) (2011) 1974-1981.

[18] R.G. Oliveira, R.Z. Wang, T. Xian Li, Adsorption characteristic of methanol in activated carbon impregnated with lithium chloride, Chemical Engineering and Technology, 33(10) (2010) 1679-1686. 
> @R.Z. Wang, J.P. Jia, Y.H. Zhu, Y. Teng, J.Y. Wu, J. Cheng, Q.B. Wang, Study on a new solid absorption refrigeration pair: Active carbon fiber-methanol, Journal of Solar Energy Engineering, 119(3) (1997) 214-218.

> @D.M. Ruthven, Principles of adsorption and adsorption processes, Wiley, New York, 1984.

> @J. Crank, Mathematics of diffusion, Oxford University Press, London, 1956.

> aD.M. Ruthven, Diffusion of oxygen and nitrogen in carbon molecular sieve, Chemical Engineering Science, 47(17-18) (1992) 4305-4308.

> @.W.W. Rutherford, J.E. Coons, Adsorption dynamics of carbon dioxide in molecular sieving carbon, Carbon, 41(3) (2003) 405-411.

> @S.W. Rutherford, J.E. Coons, Equilibrium and kinetics of water adsorption in carbon molecular sieve: Theory and experiment, Langmuir, 20(20) (2004) 8681-8687.

> @K. Uddin, I.I. El-Sharkawy, T. Miyazaki, B.B. Saha, S. Koyama, H.-S. Kil, J. Miyawaki, S.H. Yoon, Adsorption characteristics of ethanol onto functional activated carbons with controlled oxygen content, Applied Thermal Engineering, http://dx.doi.org/10.1016/j.applthermaleng.2014.03.062 (available online). 


\section{List of Figures}

Fig 1. SEM pictures of KOH4-PR and KOH6-PR adsorbent samples.

Fig 2(a). Particle size distribution of KOH4-PR adsorbent sample.

Fig 2(b). Particle size distribution of KOH6-PR adsorbent sample.

Fig. 3(a). Adsorption isotherms of KOH4-PR/ethanol pair.

Fig. 3(b). Adsorption isotherms of KOH6- PR/ethanol pair.

Fig. 4(a). Adsorption/desorption isotherm of KOH4-PR/ethanol pair at $30{ }^{\circ} \mathrm{C}$.

Fig. 4(b). Adsorption/desorption isotherm of KOH4-PR/ethanol pair at $70{ }^{\circ} \mathrm{C}$.

Fig. 4(c). Adsorption/desorption isotherm of KOH6-PR/ethanol pair at $30^{\circ} \mathrm{C}$.

Fig. 4(d). Adsorption/desorption isotherm of KOH6-PR/ethanol pair at $70{ }^{\circ} \mathrm{C}$.

Fig. 5(a). Profiles of adsorption uptake and pressure for KOH4-PR/ethanol pair at adsorption temperature $30^{\circ} \mathrm{C}$.

Fig. 5(b). Profiles of adsorption uptake and pressure for KOH6-PR/ethanol pair at adsorption temperature $30^{\circ} \mathrm{C}$.

Fig. 6(a). Plot of $\ln (1-F)$ versus time for $\mathrm{KOH} 4-\mathrm{PR} /$ ethanol pair at adsorption temperature of $30{ }^{\circ} \mathrm{C}$ and evaporator pressure of $3.5 \mathrm{kPa}$.

Fig. 6(b). Plot of $\ln (1-\mathrm{F})$ versus time for KOH6-PR/ethanol pair at adsorption temperature of $30^{\circ} \mathrm{C}$ and evaporator pressure of $3.6 \mathrm{kPa}$.

Fig. 7. Arrhenius plot of the studied pairs.

Fig. 8(a). Plot of $\mathrm{q}_{\mathrm{st}}$ versus adsorption uptake for KOH4-PR/ethanol pair.

Fig. 8(b). Plot of $\mathrm{q}_{\mathrm{st}}$ versus adsorption uptake for KOH6-PR/ethanol pair. 


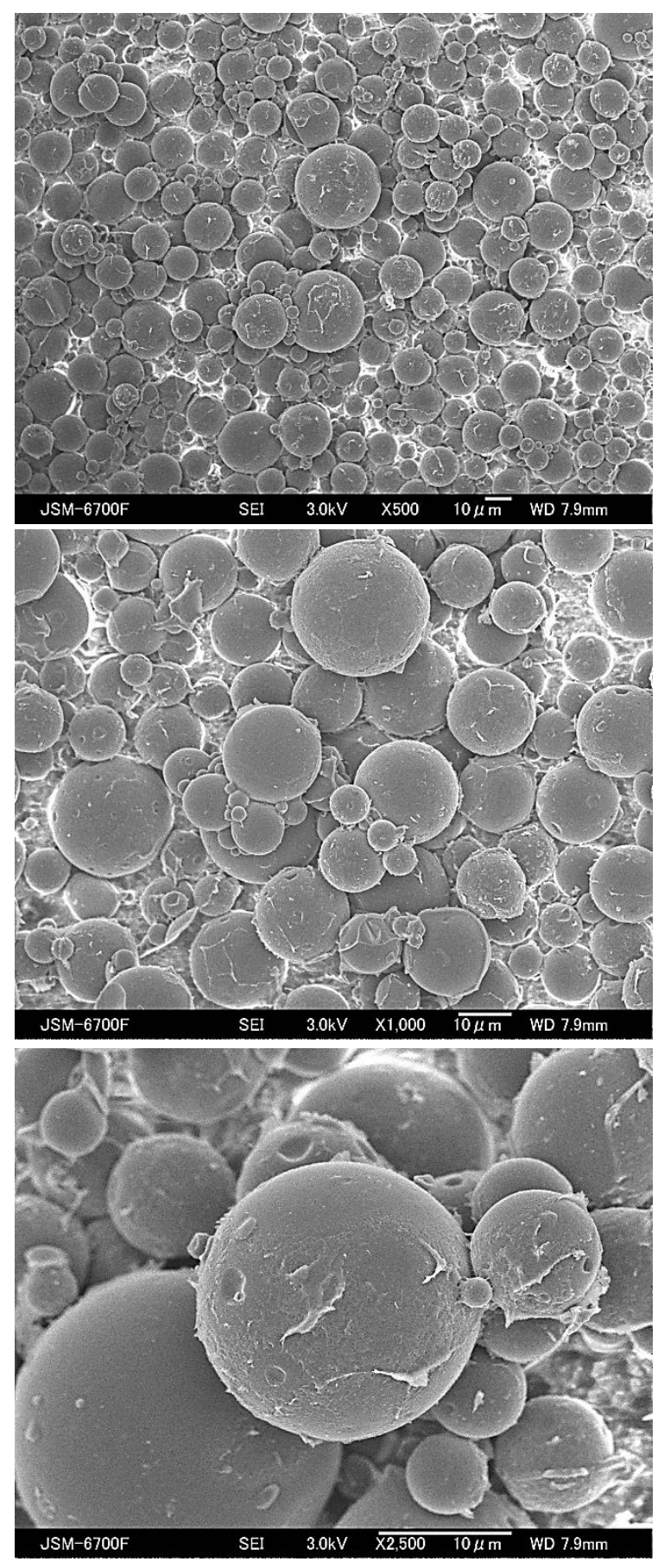

KOH4-PR
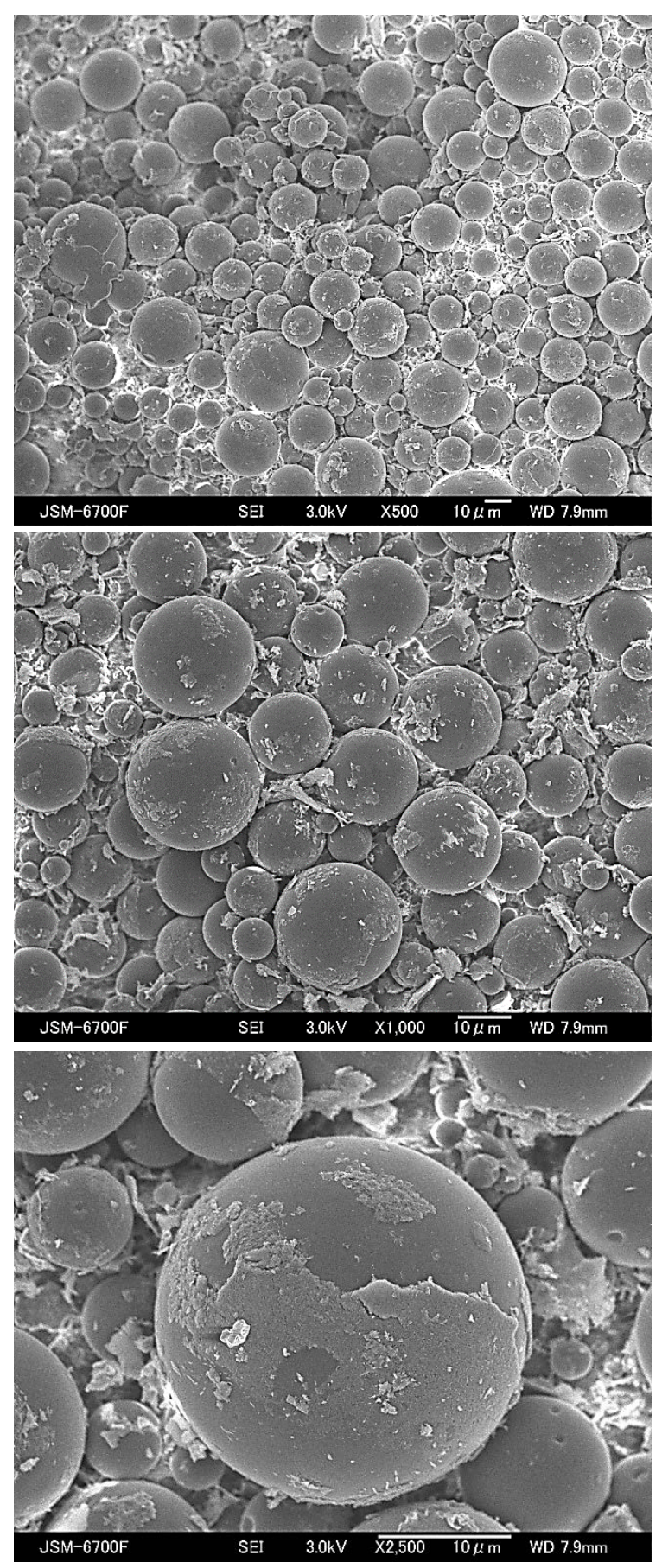

KOH6-PR

Fig 1. SEM pictures of KOH4-PR and KOH6-PR adsorbent samples. 


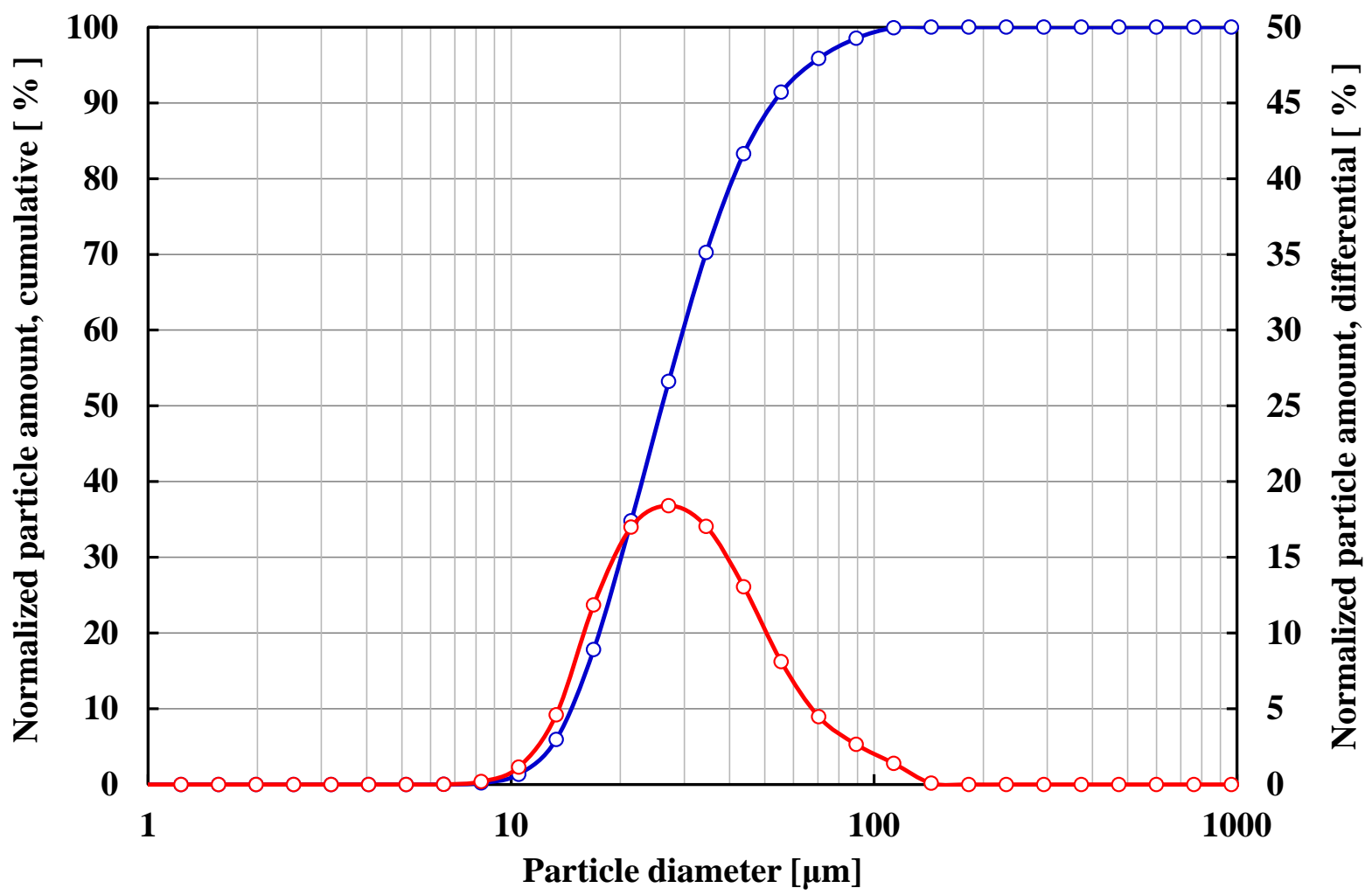

Fig 2(a). Particle size distribution of $\mathrm{KOH} 4-\mathrm{PR}$ adsorbent sample. 




Fig 2(b). Particle size distribution of KOH6-PR adsorbent sample. 


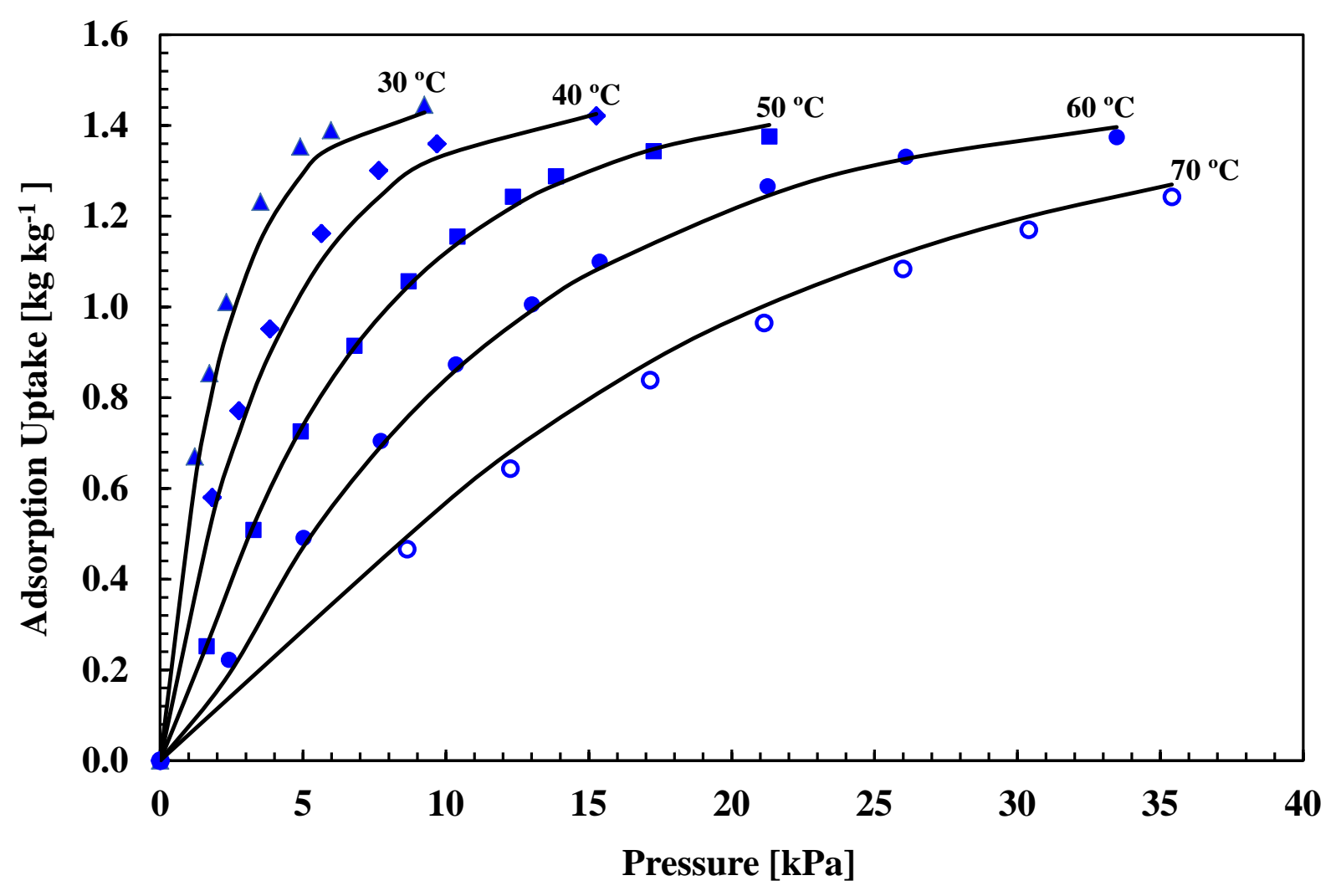

Fig. 3(a). Adsorption isotherms of KOH4-PR/ethanol pair. 




Fig. 3(b). Adsorption isotherms of KOH6-PR/ethanol pair. 




Fig. 4(a). Adsorption/desorption isotherm of $\mathrm{KOH} 4-\mathrm{PR} /$ ethanol pair at $30^{\circ} \mathrm{C}$. 


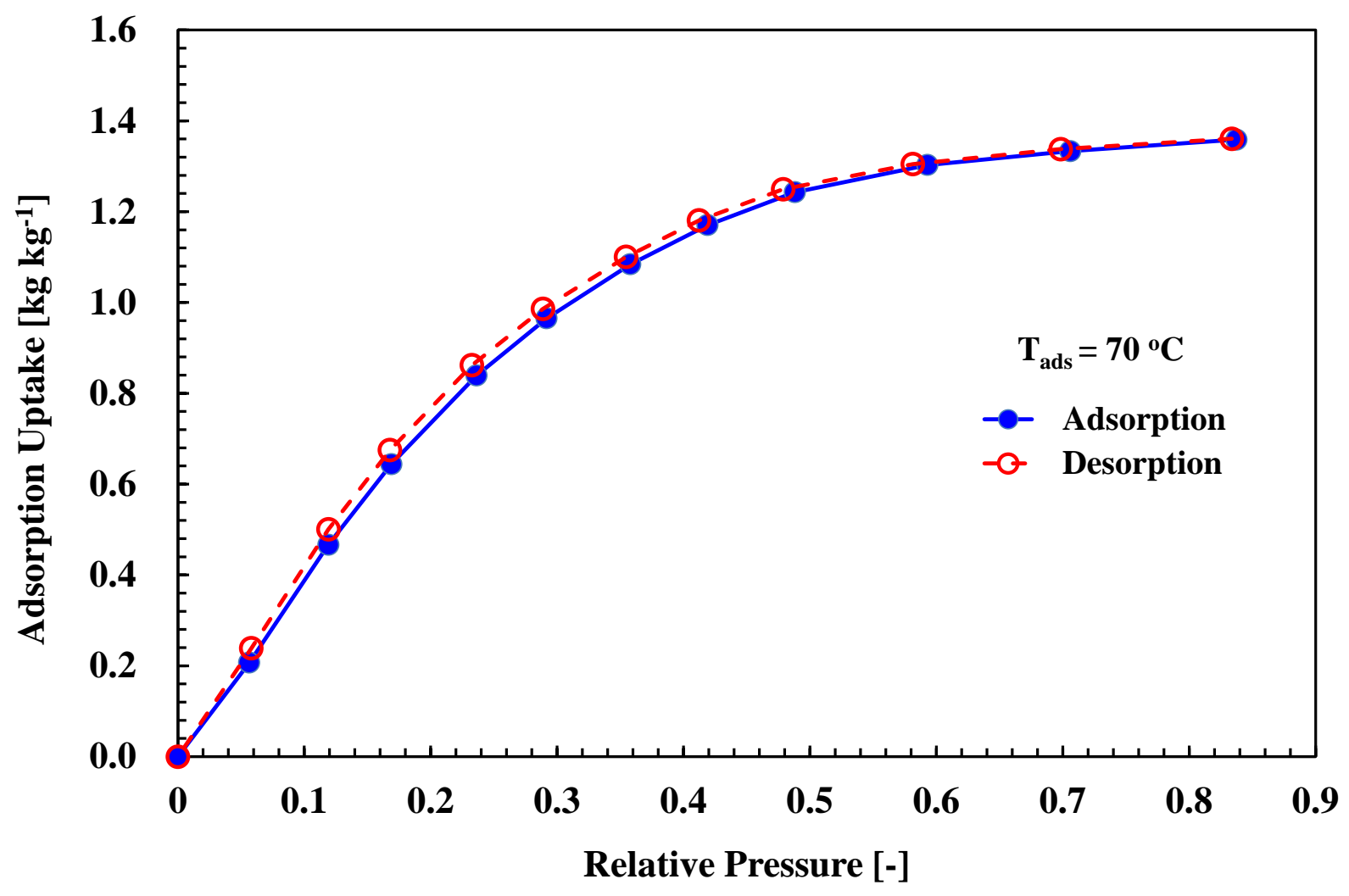

Fig. 4(b). Adsorption/desorption isotherm of KOH4-PR/ethanol pair at $70{ }^{\circ} \mathrm{C}$. 


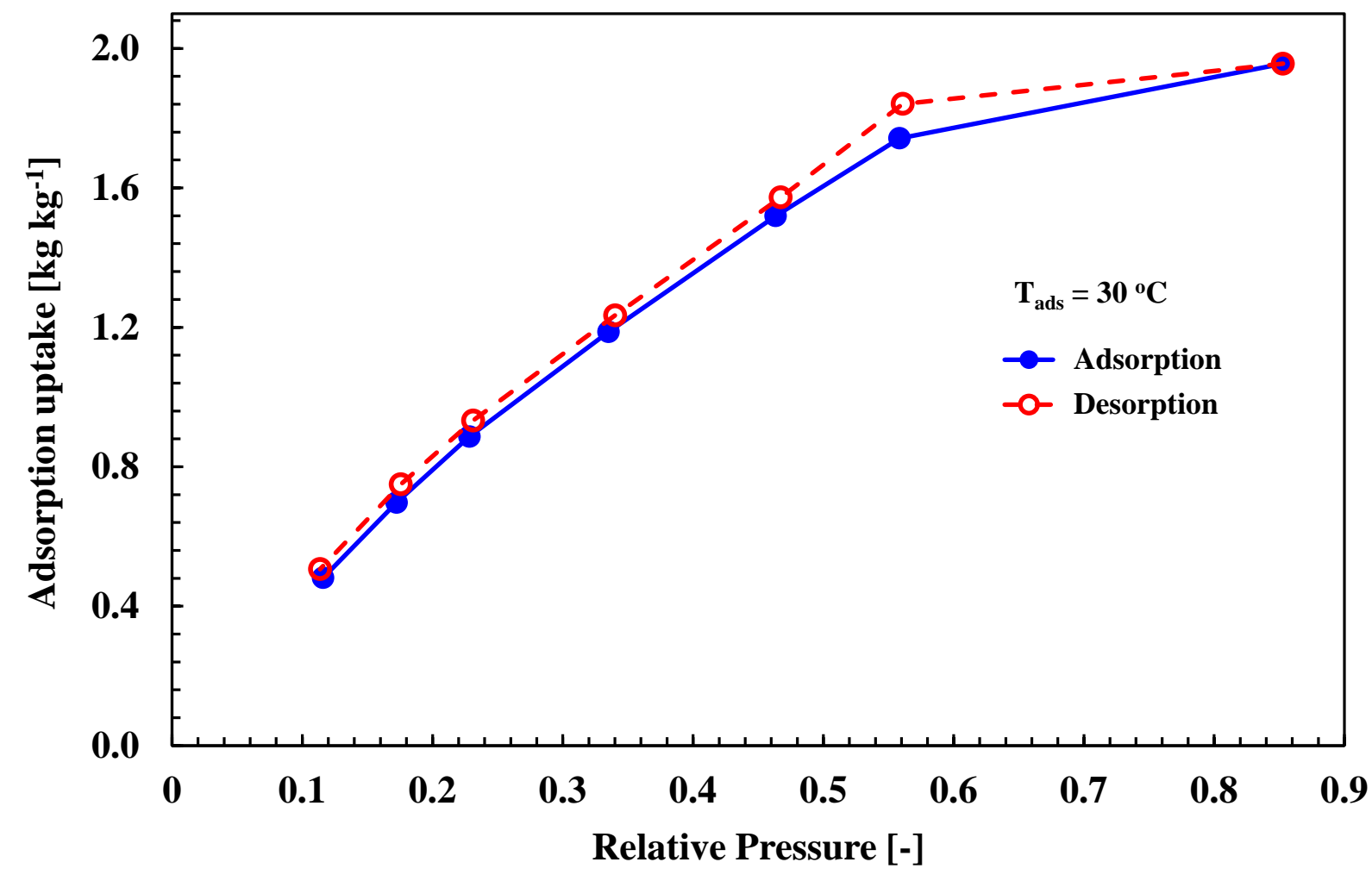

Fig. 4(c). Adsorption/desorption isotherm of KOH6-PR/ethanol pair at $30^{\circ} \mathrm{C}$. 


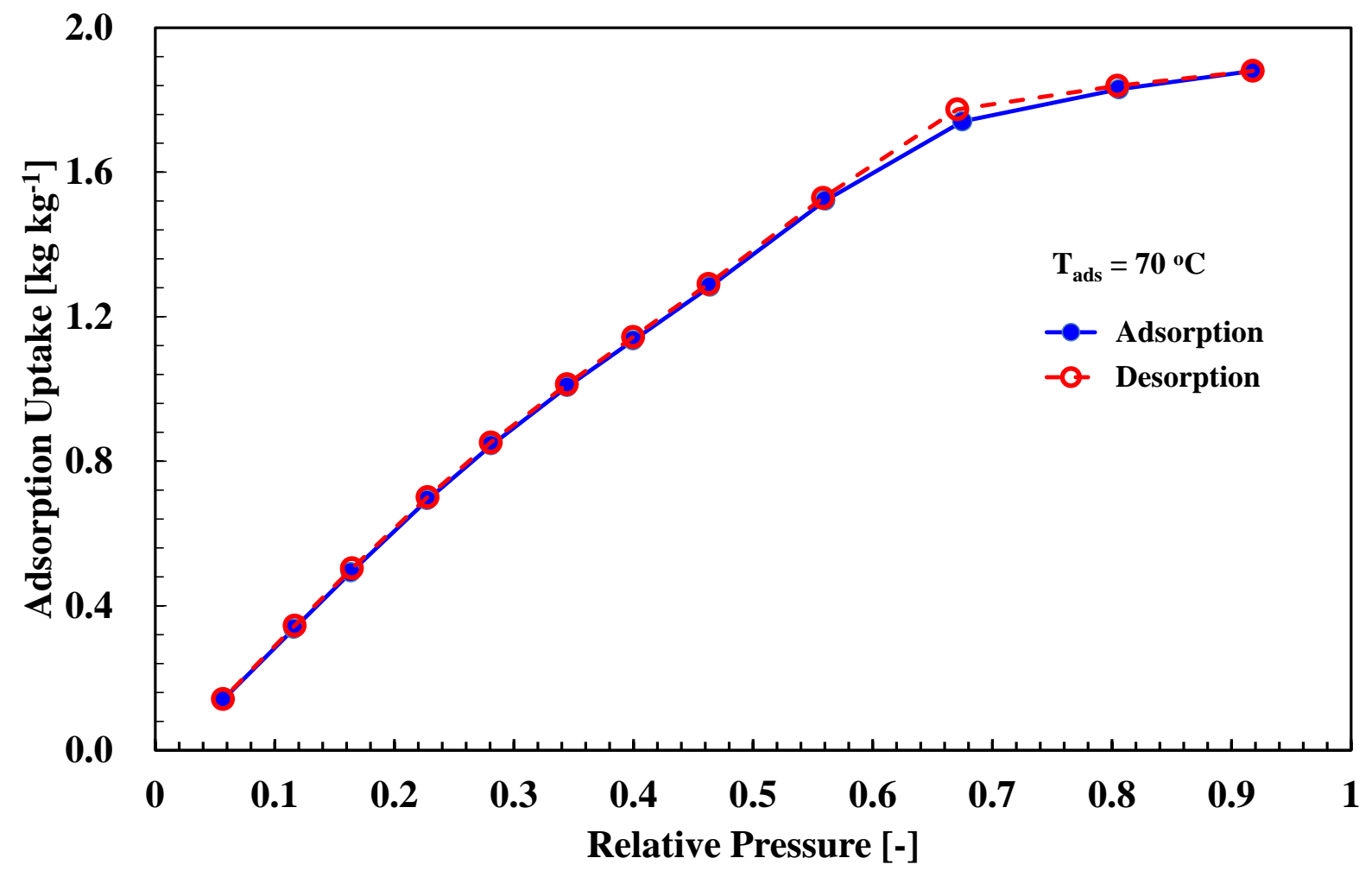

Fig. 4(d). Adsorption/desorption isotherm of KOH6-PR/ethanol pair at $70{ }^{\circ} \mathrm{C}$. 




Fig. 5(a). Profiles of adsorption uptake and pressure for KOH4-PR/ethanol pair at adsorption temperature $30^{\circ} \mathrm{C}$. 




Fig. 5(b). Profiles of adsorption uptake and pressure for KOH6-PR/ethanol pair at adsorption temperature $30^{\circ} \mathrm{C}$. 


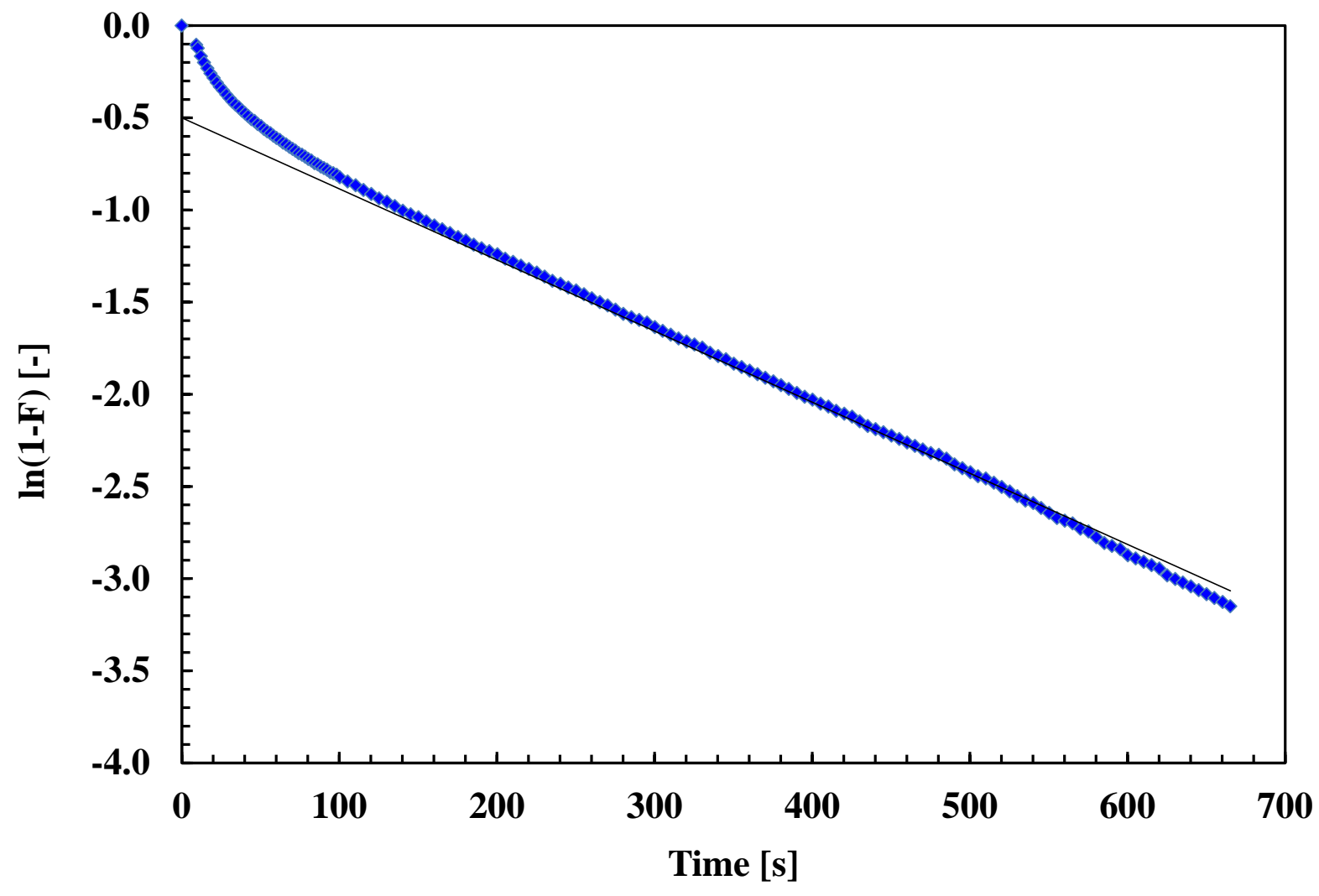

Fig. 6(a). Plot of $\ln (1-F)$ versus time for $\mathrm{KOH} 4-\mathrm{PR} /$ ethanol pair at adsorption temperature of $30^{\circ} \mathrm{C}$ and evaporator pressure of $3.5 \mathrm{kPa}$. 




Fig. 6(b). Plot of $\ln (1-\mathrm{F})$ versus time for KOH6-PR/ethanol pair at adsorption temperature of $30^{\circ} \mathrm{C}$ and evaporator pressure of $3.6 \mathrm{kPa}$. 


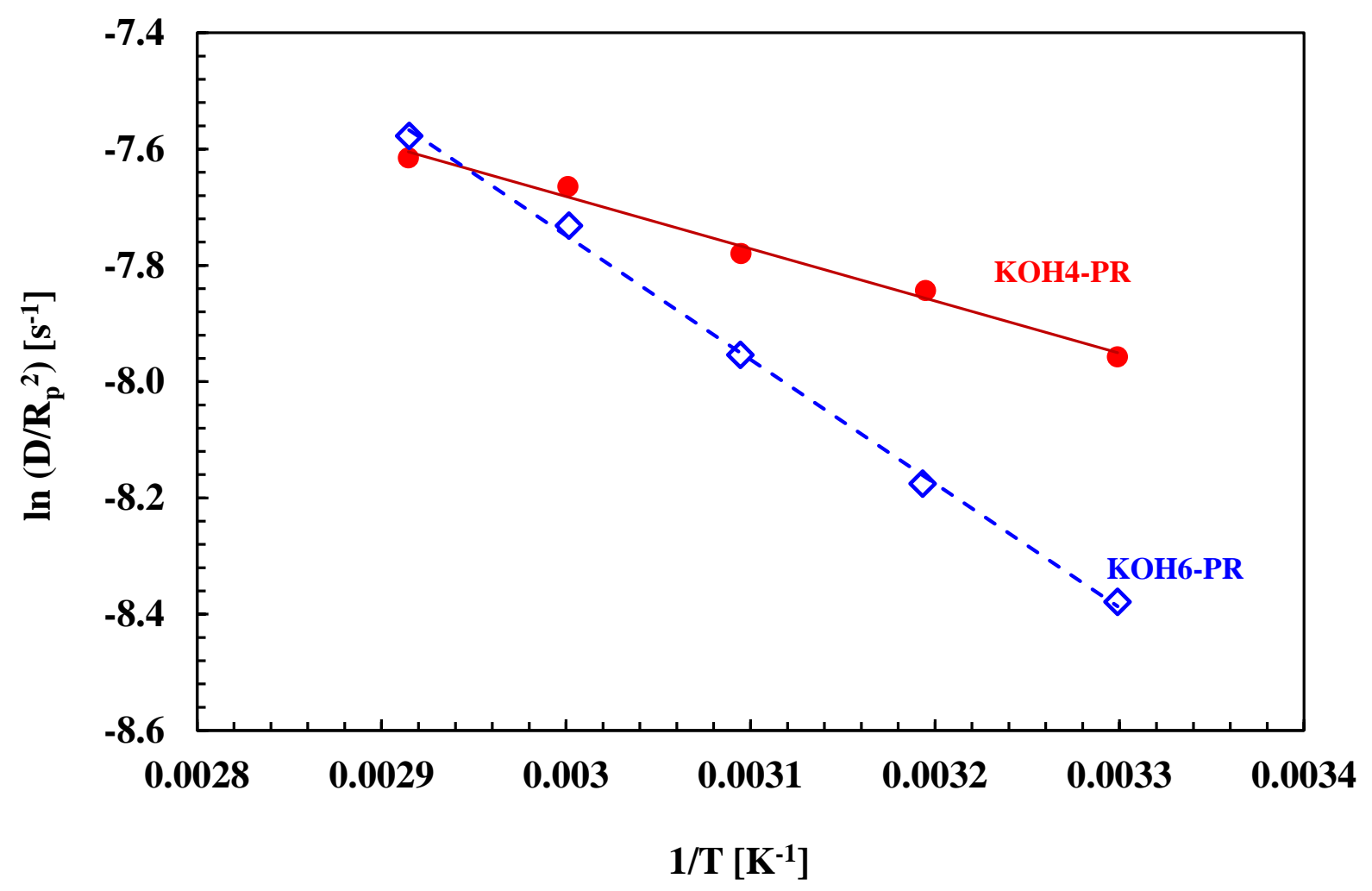

Fig. 7. Arrhenius plot of the studied pairs. 


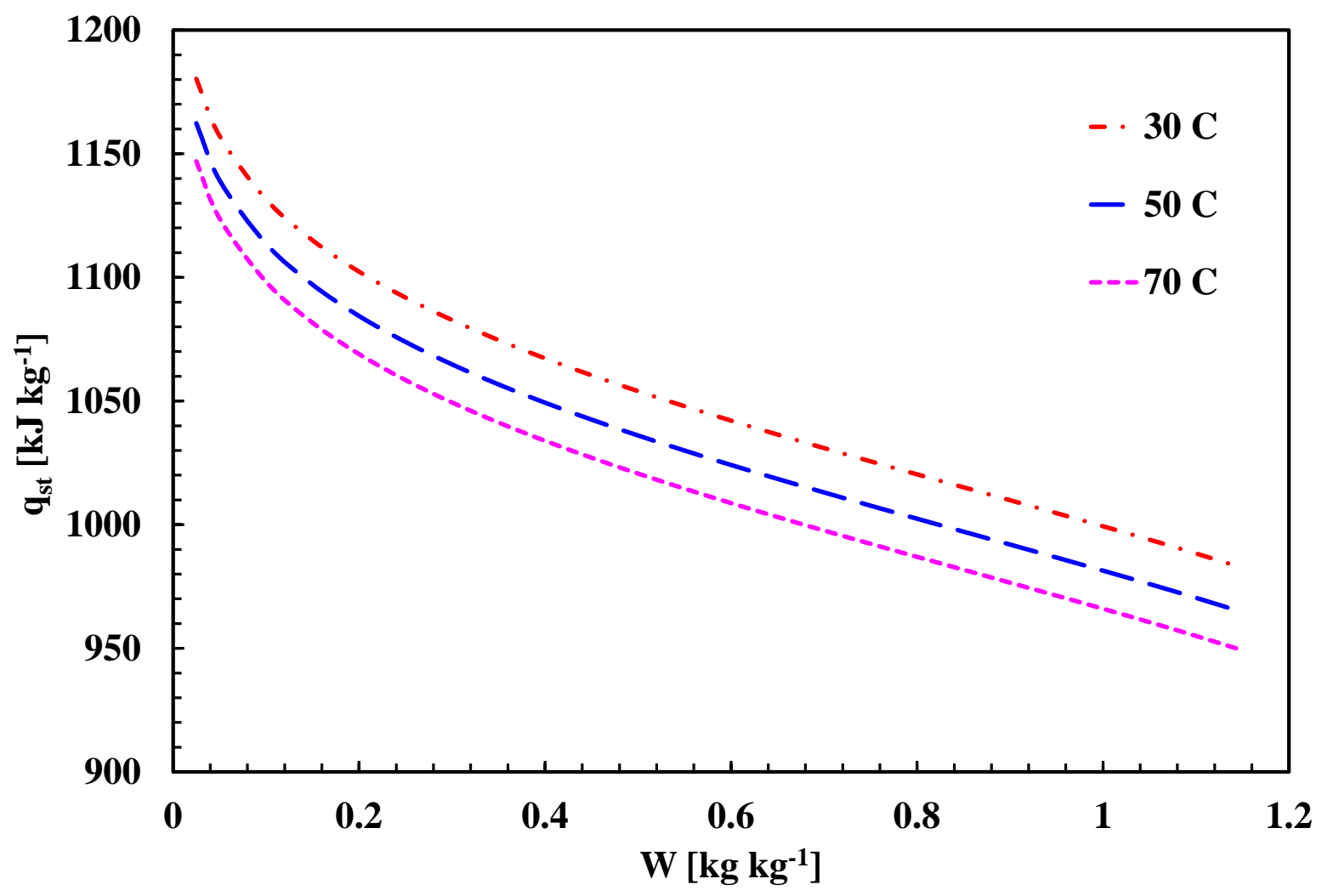

Fig. 8(a). Plot of $\mathrm{q}_{\mathrm{st}}$ versus adsorption uptake for $\mathrm{KOH} 4-\mathrm{PR} / \mathrm{ethanol}$ pair. 


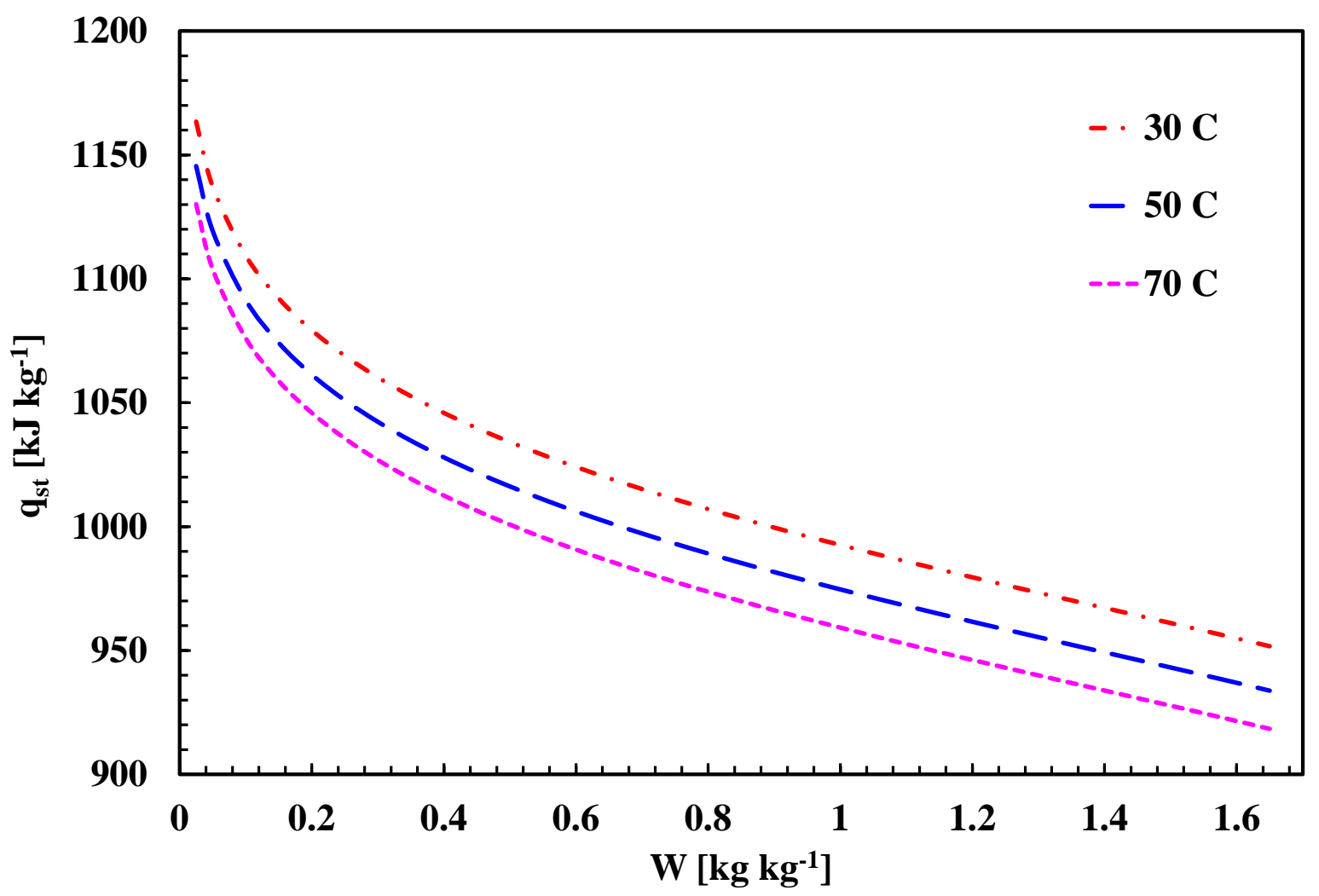

Fig. 8(b). Plot of $\mathrm{q}_{\mathrm{st}}$ versus adsorption uptake for KOH6-PR/ethanol pair. 


\section{$\underline{\text { List of Tables }}$}

Table 1 Porosity and elemental composition of the studied adsorbents.

Table 2 Isotherm parameters of ethanol adsorption onto KOH4-PR and KOH6-PR adsorbents.

Table 3 Parameters of Arrhenius equation of ethanol adsorption onto the KOH4-PR and KOH6-PR adsorbents. 


\section{Table 1}

Porosity and elemental composition of the studied adsorbents.

Adsorbent

\begin{tabular}{|c|c|c|c|}
\hline \multirow{5}{*}{  } & $\begin{array}{l}\text { Total surface area } \\
\qquad\left[\mathrm{m}^{2} \mathrm{~g}^{-1}\right]\end{array}$ & 3060 & 2910 \\
\hline & $\begin{array}{c}\text { External surface area } \\
\qquad\left[\mathrm{m}^{2} \mathrm{~g}^{-1}\right]\end{array}$ & 20 & 70 \\
\hline & $\begin{array}{l}\text { Total pore volume } \\
\qquad\left[\mathrm{cm}^{3} \mathrm{~g}^{-1}\right]\end{array}$ & 1.90 & 2.53 \\
\hline & $\begin{array}{l}\text { Micropore volume } \\
\qquad\left[\mathrm{cm}^{3} \mathrm{~g}^{-1}\right]\end{array}$ & 1.85 & 2.37 \\
\hline & $\begin{array}{c}\text { Average pore width } \\
\qquad[\mathrm{nm}]\end{array}$ & 1.25 & 1.78 \\
\hline \multirow{6}{*}{ 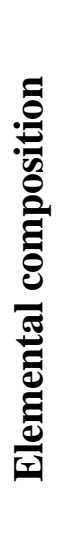 } & $\mathrm{C}$ [wt. \%] & 95.37 & 92.72 \\
\hline & $\mathrm{H}$ [wt. \%] & 0.05 & 0.10 \\
\hline & $\mathrm{N}$ [wt. \%] & 0.18 & 0.22 \\
\hline & $\mathrm{O}_{\text {diff }}[\mathrm{wt} . \%]$ & 4.40 & 5.43 \\
\hline & $\mathrm{O} / \mathrm{C}$ & 0.035 & 0.044 \\
\hline & Ash [wt \%] & - & 1.53 \\
\hline
\end{tabular}




\section{Table 2}

Isotherm parameters of ethanol adsorption onto KOH4-PR and KOH6-PR adsorbents.

\begin{tabular}{lccc}
\hline Adsorbent & $\begin{array}{c}\mathbf{W}_{\mathbf{o}} \\
{\left[\mathrm{kg} \mathrm{kg}^{-1}\right]}\end{array}$ & $\begin{array}{c}\mathbf{n} \\
{[-]}\end{array}$ & $\begin{array}{c}\mathbf{E} \\
{\left[\mathbf{k J ~ k g}^{-1}\right]}\end{array}$ \\
\hline KOH4-PR & 1.43 & 2 & 128 \\
KOH6-PR & 1.98 & 1.5 & 90 \\
\hline
\end{tabular}




\section{Table 3}

Parameters of Arrhenius equation of ethanol adsorption onto the KOH4-PR and KOH6-PR adsorbents.

\begin{tabular}{lcc}
\hline Adsorbent & $\begin{array}{c}\mathbf{D}_{\mathbf{s o}} / \mathbf{R}_{\mathbf{p}}{ }^{2} \\
{\left[\mathbf{s}^{-1}\right]}\end{array}$ & $\begin{array}{c}\mathbf{E}_{\mathbf{a}} \\
{\left[\mathbf{k J ~ k g}{ }^{-1}\right]}\end{array}$ \\
\hline KOH4-PR & $6.83 \times 10^{-3}$ & 169 \\
KOH6-PR & $2.60 \times 10^{-1}$ & 391 \\
\hline
\end{tabular}




\section{Graphical Abstract}
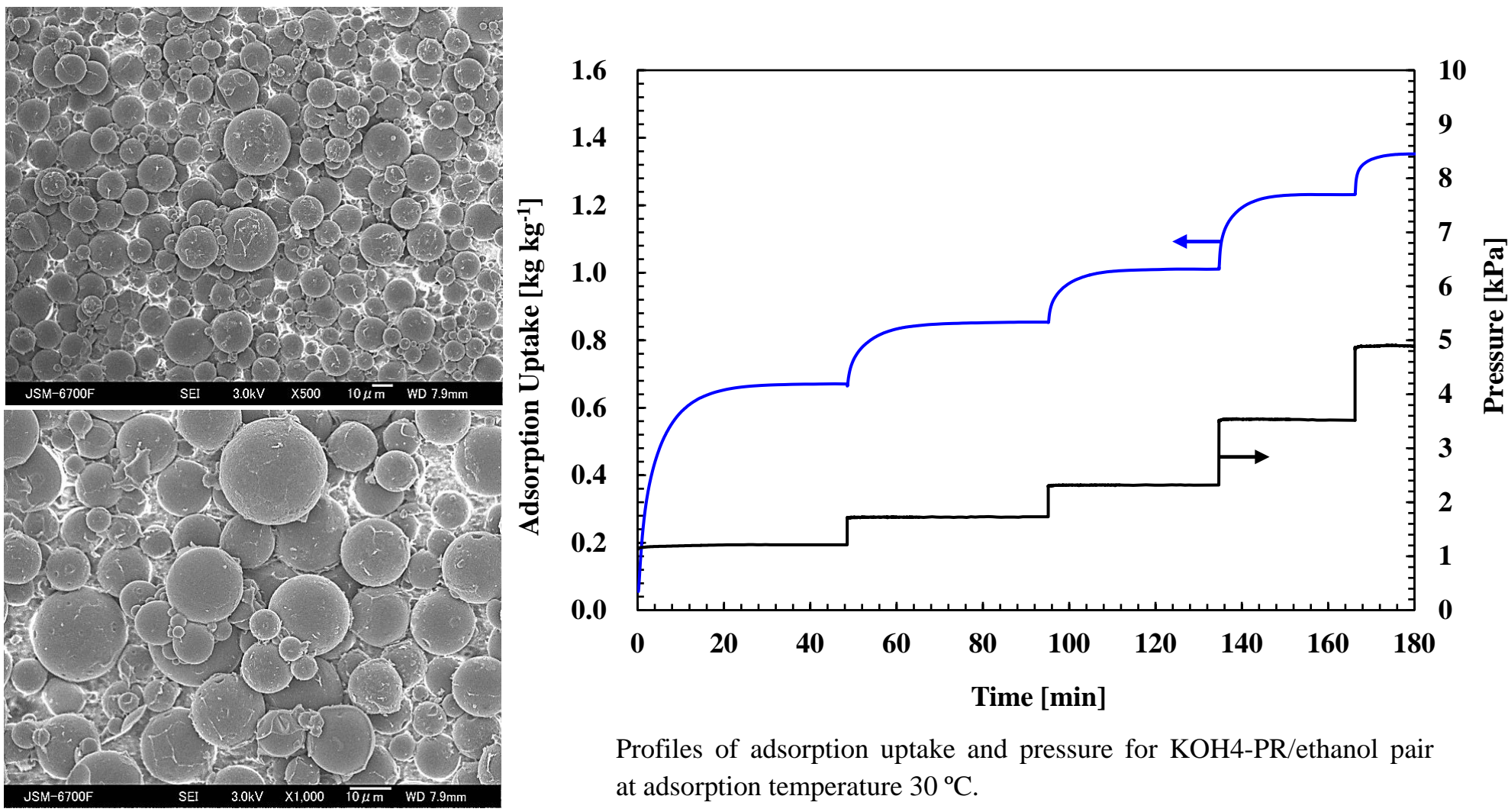

Profiles of adsorption uptake and pressure for $\mathrm{KOH} 4-\mathrm{PR} /$ ethanol pair at adsorption temperature $30^{\circ} \mathrm{C}$.

SEM picture of KOH4-PR adsorbent sample. 